\title{
Research On Light Pollution
}

\author{
Xiaomei Zhou \\ School of North China Electric Power University,Baoding 071000,China; \\ 1540169008@qq.com
}

Keywords: The light pollution, Harms ,Prevents and Controls.

\begin{abstract}
In recent years, urban construction sped up constantly,the exterior design of urban lighting system and building attached great importance in order to make the city more bright beautiful. Even if at night,lights are illuminated brilliantly, become city's scenery, moreover many buildings use the glass curtain wall and so on bright surface material as the decoration, to strengthen modernity. But these elements while are bringing beautiful to the city, similarly has also brought the serious light contamination problem day by day. For example the light that large area glass curtain wall reflect brings inconvenience to people in life or travel , night "artificial daytime" will harass the human body biological clock, creates the puzzle to the normal life.
\end{abstract}

\section{The Concept and Classification of Light Pollution.}

Light pollution is one kind of new physical property pollution, it also is called the optical interference. It refers to a phenomenon that the modern society produces unsuitable radiation's ray excessively and cause adverse effect to human life and production. The definition of "light pollution" in profession standard "Code for Design of Urban Night Scene Lighting" promulgated in our country is a general name interferential light or the excessive radiation ray (including visible light, ultraviolet and infrared light radiation)cause negative influence to the person, the ecological environment and astronomical observation and so on.

First proposed what "light pollution" is was the international astronomy, they thought that the shining behavior of urban exterior lighting to the sky creates the disturbance to the astronomical observation. On international the light pollution is divided into three kinds, namely dazzlingly bright pollution, artificial daytime and color light pollution.The light pollution has the confidentiality and harm accumulation, brings potential and continual harm to humanity and production.

\section{Sources of Light Pollution .}

\subsection{White Light Pollution.}

It is mainly because building's outer wall material's reflectance is oversized (82\%-90\%) and reflect glare. According to the determination, the white whitewashing surface's reflectance is 69-80\%. excessively strong and over withstanding scope's light definitely will cause the damage to the eye. The wall materials with high reflection factor outer have the armored glass, the glazed surface brick wall, the aluminum alloy board and so on.

\subsection{Artificial Daylight.}

Also known as night illumination. many cities attach importance to the construction of night scene, carry on "urban lighting engineering" and "the urban bright project" and so on, make the landmark buildings to shine, in addition various commercial billboards and neon lights, the entire city is brilliantly illuminated at night,the decorative lantern will also shine on the holiday. These aim at beautifying city, but have neglected the question of light pollution.

\subsection{Color Light Pollution.}

The color light pollution constitutes of the black light lamps, the revolving lights, fluorescent lamps as well as the source of color light twinkling installed in the modern dance hall. 


\section{The harm of light pollution}

\subsection{Wastes Energy and Causes Extra Pollution.}

Our country illuminates the power consumption is 143.325 - 171.99 billion kwh a year, its two-thirds are from the thermoelectricity generation,of which three-fourths is coal-fired, therefore cause the extra environmental pollution. It will produce $1100 \mathrm{~g} \mathrm{CO} 2$ and $9 \mathrm{~g} \mathrm{SO} 2$ computation every $1 \mathrm{kwh}$ electricity is produced,according to this, there are 70 - 90 million tons CO2 and 0.6-0.7 million tons SO2 every year. Therefore, the excessive urban illumination not only causes the pollution, but also wastes the resources and pollutes the environment,the loss outweighs the gain.

\subsection{Bring Inconveniences to the Residents, Even Dangers.}

Take the glass curtain walls for an example, when the sun is strong, the light that they reflects enters in person's eyes, the eye is the only organ that can feel light,therefore the injury that receives is also the worst. Uprated man-made light sources give off light , that spectral component includes infrared and ultraviolet ray, the crystal and cornea are largest to the ultraviolet ray absorbing capacity. Exposed for a long time under quartz lamps and large-scale floodlights which in containing rich ultraviolet ray will cause the electric light ophthalmia, cause the crystal to be muddy, even cataract, keratitis and conjunctivitis. If the reflected light enters in person's eyes who is doing dangerous work or vision work or driving and the light cannot diverge immediately, then it possibly will cause dangerous accidents. If people are in this kind of light pollution of the environment for a long time, they will also have neurasthenia symptoms such as a dizzy spell, losing sleep and others, the brain central nervous system will also be affected. In the summer the glass curtain walls intense reflected light enters occupy in the private residence, increase the temperature and brightness, affect the normal life seriously. Some glass curtain walls are the semicircles, the reflected light gathers a point pole to be easy to cause the fire, this is a kind of potential danger.

When the night comes, all colored lanterns that in all neon lights, billboards and buildings are lit, that causes night is similar to the daytime,it is disadvantageous and does not facilitate regarding the life of people. The glare causes the human to be hard to go to sleep at night, harasses the human body's normal biological clock, causes the working efficiency to be low at daytime. The indoor environment is also the same, black light lamp in the recreation area may have the wave length is between 250 and 320nm ultraviolet ray, its intensity substantially is higher than in the sunlight the ultraviolet ray, if the human body receives this kind of black light lamp to shine for a long time,they may have the possibility to induce the nosebleed, dedentition, even leukemia and cancer. Dance hall's neon light's blinker lights besides harming person of visual function, but may also harass the internal balance of human body, make the body's temperature, palpitation, pulse, blood pressure and so on become uncoordinated, then the hormone secretion is unbalanced, causes the brain faint dizzy and agitated restless, have a poor appetite, asthenia, losing sleep and the other light damage syndromes. The fluorescent lamp irradiation time for too long will reduce human body's calcium absorbancy, causes organism to lack the calcium.

\subsection{Disrupts the Urban Ecological Environment and Biosphere.}

The sea turtles tell the points of the compass by the stars' or the moon's reflection in water. The horses, cows and sheep judge the season of oestrus through the length of sunshine, the birds fly towards the luminous direction of stars, but the disturbances of artificial light can destroy the regular pattern, cause the animals either dead or the reproductive cycle are destroyed. Some insects have photoaxis, field of illumination will attract a lot of this kind of insects, if it is in time for the spawning-time, then the field of illumination would convergance collection massive insects, initiate the insect pest, and insect quantity change would influence the entire ecosystem through food chain . Regarding the plants, they have the obvious vegetative cycle, if disturbed by the glare in the night, its growth reproduction dormancy and so on will be affected. Some research had shown that at night the illumination of artificial ray can cause the paddy rice's mature period to postpone, growth condition get worse. 


\section{Prevents and Controls}

\subsection{Laws and Regulations}

Draw up standards of the correlation technique including laws and regulations, establish a mature management system of light pollution . At present,legal regulation do have involved the control of light pollution in our country, but national "environmental protection law" has not included the light pollution explicitly, the national and local regulations has not made concrete management measure, neither have the necessary administrative code, therefore the light contamination concern almost may say that are any laws to depend on . The lighting design specification in our country has involved the content of light contamination control , but also lacks specifications that gauge and evaluate the light pollution, therefore the formulation relevant laws and regulations are especially important regarding the active control of light pollution, otherwise, the bright area unceasingly enlarges, the populace have no place to take legal actions, only will make this kind of pollution more and more serious.

\subsection{Green Lighting}

Pursue green illume project, put the " prevent light pollution" into the urban planning policy, unify with constructing low-carbon city. Popularize green lighting techniques and products, when redacting and drawing up the correlation technique standard of master plan and ,add related contents,construct city green building illumination environment through controlling energy consumption and illumination index. Train high level professionals, they consider the illumination question comprehensively when design in the urban planning, to prevent disturbance to .

\subsection{Strengthen the Propaganda and Education .}

Enhance people's awareness of light pollution, raises everybody's rights protection consciousness,conduct propaganda related knowledge of light pollution and the advantages of using energy conservation lamps and lanterns, reducing the profit of decorative lighting illumination.As long as everyone attaches great importance, can reduce the injury that the light pollution brings, moreover can play the role of supervision and supervision, to promote the maturity of the law.

\section{Summary}

In conclusion,the effect of light pollution is significant for the human, and its harm has begun to emerge, if pay attention to governance timely, we can handle this, but if we continue build city but overlook this , pollution problems will become increasingly serious,then governance must be put on the agenda, early stage is the best period to do something above.

\section{References}

[1].Jie Liu,Xiaochun Peng,Qijia Zhong,Qiaoli Fang, et al. Countermeasures on urban light pollution control and management. Environment and sustainable development.Vol.(2012)No.4,p.65-68.

[2].Shijun Zhang, et al. Light pollution - a new type of environmental pollution. Urban Problems.Vol.(2004)No.6,p.31-34.

[3].Ti Zhou:The Research of Light Pollution Problem in Urban Lighting \& Design Countermeasure (Master's degree in Architectural Design and Theory, Central China Normal University, China, 2005) .p.22-25.

[4].Xuefeng Tang:The Experimental Research of Influence to Organism by Light Pollution (Master's degree in Optical Engineering, Nanjing University of Aeronautics and Astronautics, China, 2007) .p.11-15. 